\title{
Compression and shear wave propagation in cemented-sand specimens
}

\author{
M. F. AMARAL*, A. VIANA DA FONSECA*, M. ARROYO†, G. CASCANTE $\ddagger$ and J. CARVALHO§
}

\begin{abstract}
Ultrasonic and bender element tests in the laboratory are typically used to measure elastic modulus and damping ratio. However, interpretation of the results is challenging for a variety of reasons, including the influence of experimental details, geometrical effects and the analytical techniques used for data processing. It is therefore convenient to cross-check results by performing several independent measurements. Three different types of measurements were performed on cementedsand specimens. Longitudinal waves or constrained compressional waves in a cylindrical specimen were generated in a high-frequency range (20-70 kHz) using a newly designed transducer interface. Full dynamic characterisation was made possible by independent measurement of the transducer response. Pure unconstrained compressional waves or simply compression waves were measured in the same specimens with high-frequency transducers. The shear modulus was computed and used to predict the arrival of shear waves on independent bender element measurements. The predicted arrival was close to first-break estimates, and bender measurements were therefore confidently employed to track cement curing effects on a different set of specimens. The specimen frequency response function obtained from the longitudinal wave measurements was examined in detail and damping ratios were estimated for the compression vibration modes in a rod.
\end{abstract}

doi: 10.1680/geolett.11.00032

KEYWORDS: dynamics; geophysics; laboratory tests; soil stabilization; stiffness

ICE Publishing: all rights reserved

\section{INTRODUCTION}

Cement-improved soils are frequently employed in distinct earthworks such as transition zones between embankments and rigid structures, and subgrades for roads, platforms and railway tracks. Ideally, the soil-cement layers should be both tightly specified and thoroughly controlled. Dynamic properties (stiffness and damping) are relevant from this viewpoint, because they can be measured both in the field and in the laboratory.

Shear stiffness measurements are frequently made using bender elements because they are economical and easily implemented in laboratory testing procedures. However, it is difficult to establish reliable criteria for wave arrival and a case-by-case approach is necessary (e.g. Viana da Fonseca et al., 2009; Arroyo et al., 2010). Another area of special difficulty is damping measurements, particularly for stiffer soils such as cemented granular materials (Khan et al., 2006, Tallavó et al., 2011). There is therefore an advantage in using a redundant procedure to confirm soil dynamic measurements. This redundant procedure is demonstrated in this work using multiple dynamic measurements (e.g. compressional waves, longitudinal waves and shear waves) on cemented-soil specimens.

As part of a research programme involving the geotechnical laboratories of the Faculty of Engineering of

Manuscript received 13 July 2011; first decision 15 August 2011; accepted 7 September 2011.

Published online 30 September 2011.

* Department of Civil Engineering, University of Porto, Portugal $\dagger$ Department of Geotechnical Engineering, Barcelona Tech, Barcelona, Spain

tDepartment of Civil Engineering, University of Waterloo, Ontario, Canada

$\S$ Department of Mine and Geo-environmental Engineering, University of Porto, Portugal the University of Porto (FEUP), the University of Waterloo (UoW) and Barcelona Tech (UPC) aiming at characterising the dynamic and cyclic properties of soils/ aggregate-cement admixtures, this letter focuses on the evaluation of dynamic properties by using mechanical waves.

\section{BACKGROUND}

\section{Elastic waves}

Two different elastic wave modes are possible in homogeneous elastic solids: compression and shear modes, with motions parallel and perpendicular to the propagation direction and corresponding velocities $V_{\mathrm{P}}$ and $V_{\mathrm{S}}$, respectively. These velocities are given by

$$
\begin{aligned}
& V_{\mathrm{P}}=\left(\frac{E}{\rho} \frac{(1-v)}{(1+v)(1-2 v)}\right)^{1 / 2}=\left(\frac{M}{\rho}\right)^{1 / 2} \\
& V_{\mathrm{S}}=\left(\frac{E}{\rho} \frac{1}{2(1+v)}\right)^{1 / 2}=\left(\frac{G}{\rho}\right)^{1 / 2}
\end{aligned}
$$

where $\rho$ is the material mass density and $E, M, G$ and $v$ represent Young's modulus, the constrained modulus, shear modulus and Poisson's ratio, respectively. In finite bodies, elastic wave propagation is constrained by the boundaries. For axial propagation in a cylinder, an infinite number of longitudinal, flexural and torsional modes are all possible (Thurston, 1992). At low frequencies, the fundamental longitudinal mode propagates with the same velocity as that characterising a system (e.g. 'bar' or 'rod') where only longitudinal motions are allowed (Kolsky, 1953; Graff, 1991). In these conditions, the compression 
Table 1. Main characteristics of the different soil-cement mixtures

\begin{tabular}{|c|c|c|c|c|c|c|c|c|}
\hline & \multicolumn{8}{|c|}{ Specimen } \\
\hline & 1 & 2 & 3 & 4 & 5 & 6 & 7 & 8 \\
\hline Cement/soil weight: $\%$ & $2 \cdot 00$ & $3 \cdot 00$ & $5 \cdot 00$ & $7 \cdot 00$ & $2 \cdot 00$ & $3 \cdot 00$ & $5 \cdot 00$ & $7 \cdot 00$ \\
\hline Cement/soil volume: $\%$ & $1 \cdot 79$ & $2 \cdot 71$ & $4 \cdot 62$ & $6 \cdot 60$ & $1 \cdot 79$ & $2 \cdot 71$ & $4 \cdot 62$ & $6 \cdot 60$ \\
\hline Density: $\mathrm{kg} / \mathrm{m}^{3}$ & 1876 & 2046 & 1973 & 1878 & 1858 & 2049 & 1975 & 1877 \\
\hline Dry density: $\mathrm{kg} / \mathrm{m}^{3}$ & 1679 & 1839 & 1760 & 1663 & 1656 & 1836 & 1765 & 1672 \\
\hline Water content: $\%$ & $11 \cdot 7$ & $11 \cdot 3$ & $12 \cdot 1$ & $12 \cdot 9$ & $12 \cdot 2$ & $11 \cdot 6$ & $11 \cdot 9$ & $12 \cdot 3$ \\
\hline Saturation degree: $\%$ & 50 & 62 & 58 & 52 & 51 & 64 & 57 & 50 \\
\hline Void ratio & $0 \cdot 624$ & $0 \cdot 485$ & $0 \cdot 556$ & $0 \cdot 651$ & $0 \cdot 647$ & $0 \cdot 487$ & 0.551 & 0.642 \\
\hline Porosity & $0 \cdot 384$ & $0 \cdot 327$ & $0 \cdot 357$ & $0 \cdot 394$ & $0 \cdot 393$ & $0 \cdot 328$ & $0 \cdot 355$ & $0 \cdot 391$ \\
\hline$\eta / C_{\mathrm{IV}} 0 \cdot 21$ & $0 \cdot 994$ & $0 \cdot 762$ & $0 \cdot 755$ & $0 \cdot 785$ & $1 \cdot 019$ & $0 \cdot 764$ & $0 \cdot 750$ & 0.778 \\
\hline
\end{tabular}

velocity is governed by $E$ instead of $M$, is known as the longitudinal or rod velocity $V_{\mathrm{L}}$ and is given by

$$
V_{\mathrm{L}}=\left(\frac{E}{\rho}\right)^{1 / 2}
$$

Since the three velocities $V_{\mathrm{P}}, V_{\mathrm{S}}, V_{\mathrm{L}}$ depend on two independent elastic constants $(E$ and $v)$ and the mass density, independent measurement of the two elastic constants is sufficient to predict the three velocities.

\section{Measurement system characterisation}

The soil experimental characterisation through seismic measurements is advantageously framed using a linear systems perspective (Santamarina \& Fratta, 2005). Wave transmission tests are represented by a system relating input and output signals. This will be composed of different series-connected subsystems representing, for instance, the input electronics, driving transducers, specimen, receiving transducer and output electronics. Any subset of these components can be fully characterised in the time domain by its impulse response function (IRF). The IRF relates dynamic inputs $(X(t))$ and outputs $(Y(t))$ through a convolution product (Ewins, 1991)

$$
Y(t)=X(t)^{*} \operatorname{IRF}(t)=\int_{-\infty}^{\infty} X(s) \times \operatorname{IRF}(t-s) \mathrm{d} s
$$

A Fourier transform of the IRF gives the frequency response function (FRF), which relates the transformed dynamic input $(X(\omega))$ and output $(Y(\omega))$ through the simple product $\omega=2 \pi f$, where $f$ is frequency

$$
Y(\omega)=X(\omega) \times \mathrm{FRF}(\omega)
$$

In principle, if the testing hardware can be separately characterised, this relation would allow the isolation or deconvolution of the specimen transmission effects through relations of the type

$$
\begin{aligned}
& \mathrm{FRF}_{\text {specimen }}= \\
& \frac{\mathrm{FRF}_{\text {electronics }} \times \mathrm{FRF}_{\text {transducers }} \times \mathrm{FRF}_{\text {specimen }}}{\mathrm{FRF}_{\text {electronics }} \times \mathrm{FRF}_{\text {transducers }}}= \\
& \frac{\mathrm{FRF}_{\mathrm{TSR}}}{\mathrm{FRF}_{\mathrm{TR}}}=\mathrm{FRF}_{\mathrm{S}}
\end{aligned}
$$

For piston-like contact transducers, this approach has recently been proposed by Tallavó et al. (2011).

\section{Damping ratio $\xi_{\mathrm{k}}$}

Direct inspection of the FRF spectrum allows identification of the damping ratio associated with any resonant mode (spectral peak) of the system using the half-power bandwidth method (Kramer, 1996)

$$
\xi_{\mathrm{k}}=\frac{f_{2}-f_{1}}{f_{2}+f_{1}}
$$

where $f_{1}$ and $f_{2}$ are the lower and upper frequencies found at magnitude $1 / 2^{0 \cdot 5}$ below the peak.

\section{MATERIALS AND METHODS}

Several cemented granular materials were created by mixing cement, water and silty sand. The silty sand is the weathering product of Porto granite. This is a well-characterised soil (Viana da Fonseca et al., 2006; Amaral, 2009), classified as $\mathrm{SM}$ in the unified classification system, and is very well graded with about $30 \%$ of fines; particle density is $2.72 \mathrm{~g} / \mathrm{cm}^{3}$. The effective diameter $\left(D_{50}\right)$ is $0.25 \mathrm{~mm}$; uniformity and curvature coefficients are 113 and $2 \cdot 7$, respectively. Tap water and high initial strength Portland cement (CEM I 52.5 $\mathrm{R}$; specific gravity $3 \cdot 1$ ) were mixed with it.

Mixture proportions were established by weight. Four distinct cement percentages $C$ were employed: 2, 3, 5 and 7\% of the soil dry weight. An effort was made to maintain the grain size distribution of the original soil by subtracting the same weight of fines as the added cement. Water content $w$ was established to approach $12 \%$, the optimum of the modified Proctor test for mixtures with 3\% cement (Rios Silva et al., 2009). Target densities were established to cover a range of $\eta / C_{\mathrm{IV}}{ }^{0.21}$ values (see Table 1), where $\eta$ is porosity and $C_{\mathrm{IV}}$ is the volumetric ratio of cement and dry soil. This is a mixture characterisation index (Consoli et al., 2009) that shows good correlation with mechanical response.

Eight specimens, two for each mixture type, were moulded into cylinders of $71 \mathrm{~mm}$ diameter and $137 \mathrm{~mm}$ height. Four specimens (one for each mixture) were tested at UoW (specimens 1 to 4 ) and the other four were tested at FEUP (specimens 5 to 8).

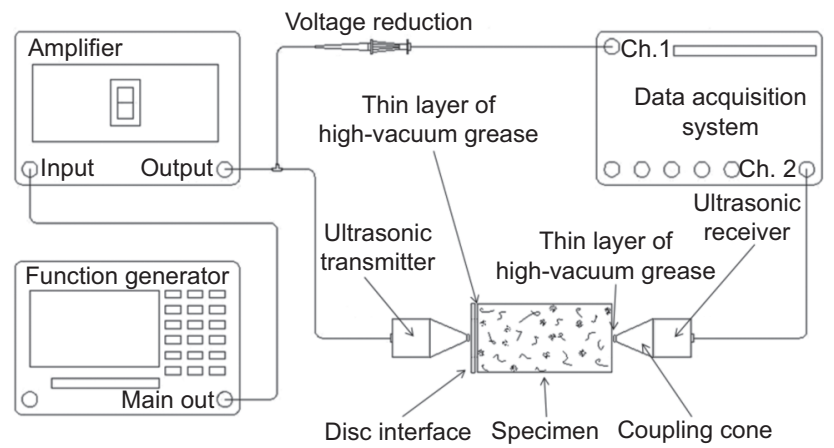

Fig. 1. Use of the soil-cement disc interface and system configuration to determine $\mathrm{FRF}_{\mathrm{TSR}}$ 


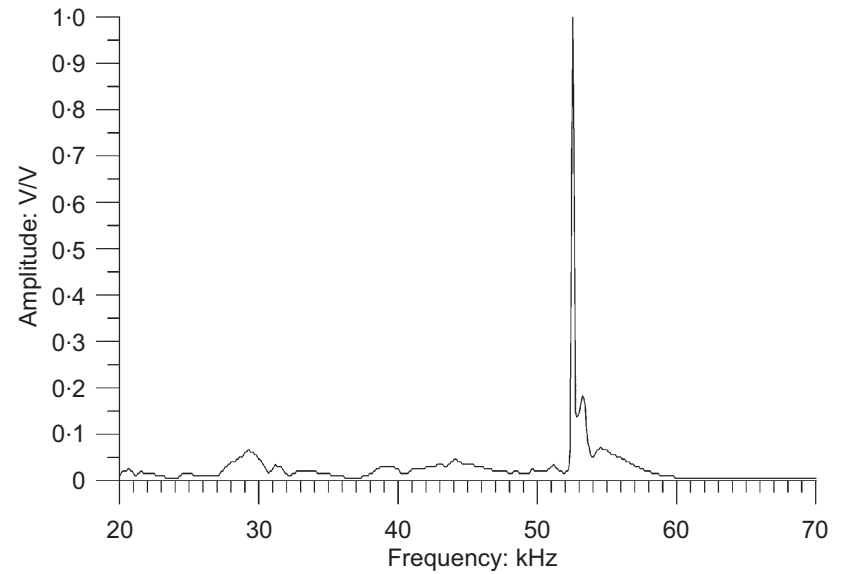

Fig. 2. Longitudinal wave measurement: $\mathrm{FRF}_{\mathrm{S}}$ of specimen 3 without soil-cement disc interface

The mixture was statically compacted in three layers (Rios Silva et al., 2009). After compaction, the specimens were stored at $96 \%$ relative humidity and $23^{\circ} \mathrm{C}$ for 7 days. Specimens 1 to 4 were tested after a curing period of 28 days. Physical conditions led to compression and longitudinal wave measurements. Specimens 5 to 8 were tested at 7, 14, 21 and 28 days, with recourse to bender/extender elements (Lings \& Greening, 2001). The intermediate tests took place over a sufficiently short duration (1-2 h) so as not to alter the curing process.

\section{Dynamic testing}

Longitudinal wave velocity. The system used (Fig. 1) is described by Tallavó et al. (2011). The base piston transducers (CNS Farnell UTR50) had a nominal $50 \mathrm{kHz}$ frequency. The data acquisition system used was WaveBook 516ETM. A $50 \mathrm{kHz}$ sine pulse was created by a function generator (HP 33120A) and amplified before reaching the transducer.

Two aluminium cones had been adapted to the transducers by Tallavó et al. (2011) to reduce piston near-field effects. These cones were $63 \mathrm{~mm}$ high and the coupling reduced the diameter of the transducer to $10 \mathrm{~mm}$. However, these cones appeared unsuitable for generating the uniform cross-sectional motion associated with longitudinal waves. To ensure uniform motion, a disc made of the same material as the soil-cement specimens was included between the transmitter and specimen (Fig. 1). A same-material disc promotes the least possible wave reflections in the specimendisc interface once $E$ remains constant.

Measurements were taken with and without a specimen in order to characterise separately the dynamics of the testing system. The effect of the disc on the frequency response of the specimens is illustrated in Figs 2 and 6. Without the disc (Fig. 2), the spectral response is overwhelmed around $50 \mathrm{kHz}$; with the disc (Fig. 6) the dynamic response of the specimen is much richer. An anti-resonant transmitter/receiver (without the disc) response explains the peak in Fig. 2 (see equation (6)). Note that the examined frequency range $(20-70 \mathrm{kHz})$ was conditioned by the transducer's response spectra.

Arrival times for the longitudinal wave were established by obtaining the IRF of the specimen, obtained by the inverse Fourier transform of the $\mathrm{FRF}_{\mathrm{S}}$ routine, and establishing the time delay on their traces. Cross-checks were made to ensure that, effectively, the time delay corresponding to the whole system IRF $F_{\text {TSR }}$ (transmitter-specimen-receiver) was similar to the sum of the time delay of the transmitter-receiver

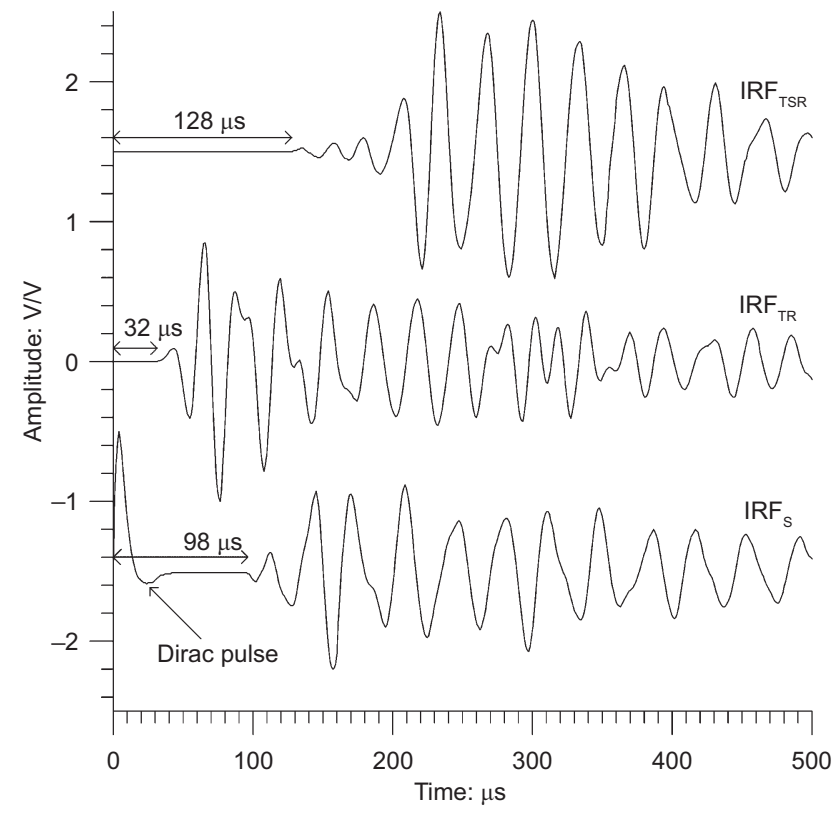

Fig. 3. Longitudinal wave measurements and times of propagation of $I R F_{T S R}, I R F_{T R}$ and IRF $F_{S}$. Deconvolution example for specimen 4

$\left(\mathrm{IRF}_{\mathrm{TR}}\right)$ plus that of the specimen (IRF $)$. Fig. 3 shows one example of these measurements.

Compression wave velocity. The system for the measurement of compression waves included a function generator (Panametrics 5052PR), a pair of piston transducers (Panametrics $1 \mathrm{MHz}$ ), an oscilloscope (HP 54645A) and amplification before the source. The transducers were kept horizontally in contact with the specimen.

A $1 \mathrm{MHz}$ ramp pulse was input to the system. Visual examination of the output signal enabled a first-break identification of the arrival time. The travelling wave was interpreted as a confined compression wave. A $1 \mu$ s system delay was established by calibrating the system with a series of steel dummies of variable height (Khan et al., 2011). The measurement traces are shown in Fig. 4.

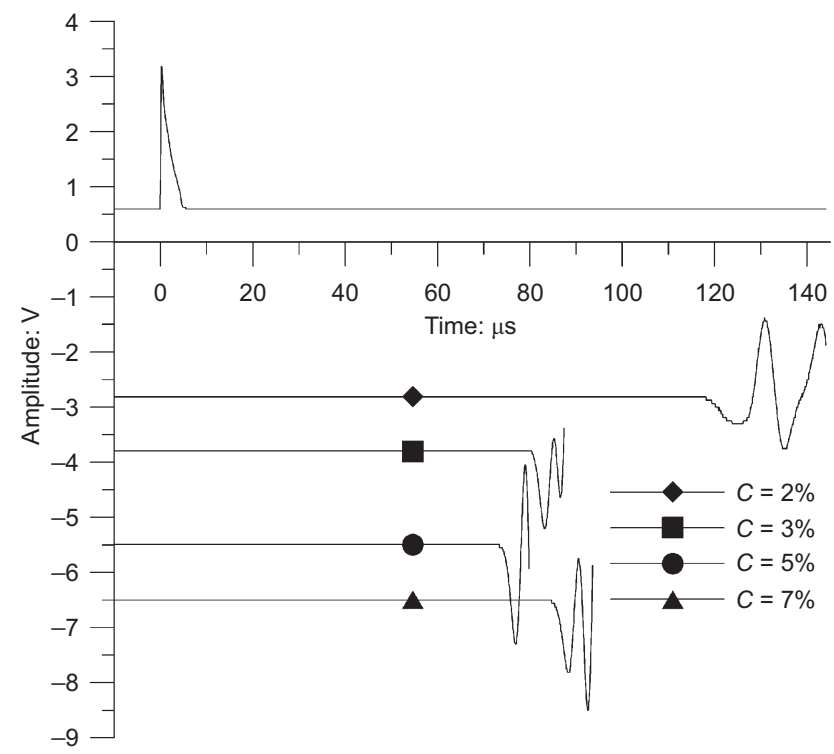

Fig. 4. Compression wave propagation measurements 
Table 2. Results from the longitudinal in a rod $(L)$ and compression $(P)$ wave measurements at UoW

\begin{tabular}{|c|c|c|c|c|}
\hline & \multicolumn{4}{|c|}{ Specimen } \\
\hline & 1 & 2 & 3 & 4 \\
\hline $\begin{array}{l}\text { Density: } \mathrm{kg} / \mathrm{m}^{3} \\
\text { Longitudinal wave's time of propagation: } \mu \mathrm{s} \\
\text { Longitudinal wave velocity: } \mathrm{m} / \mathrm{s} \\
\text { Young's modulus: MPa } \\
\text { Longitudinal wavelength: mm } \\
\text { Compression wave time of propagation: } \mu \mathrm{s} \\
\text { Compression wave velocity: } \mathrm{m} / \mathrm{s} \\
\text { Constrained modulus: MPa } \\
\text { Poisson's ratio } \\
\text { Shear modulus: MPa }\end{array}$ & $\begin{array}{l}1857 \\
131 \\
1042 \\
2016 \\
20 \cdot 84 \\
118 \cdot 2 \\
1159 \\
2493 \\
0 \cdot 26 \\
800\end{array}$ & $\begin{array}{c}2046 \\
89 \\
1536 \\
4825 \\
30 \cdot 72 \\
80 \cdot 4 \\
1704 \\
5942 \\
0 \cdot 26 \\
1915\end{array}$ & $\begin{array}{c}1973 \\
82 \\
1678 \\
5556 \\
33 \cdot 56 \\
73 \cdot 4 \\
1867 \\
6878 \\
0 \cdot 27 \\
2187\end{array}$ & $\begin{array}{l}1878 \\
97 \\
1404 \\
3702 \\
28 \cdot 08 \\
84 \cdot 7 \\
1617 \\
4912 \\
0 \cdot 29 \\
1435\end{array}$ \\
\hline
\end{tabular}

Bender element tests. Bender elements mounted on steel plates were placed in contact with the top and bottom of the cylindrical specimens. Difficulties with transducer insertion into the sample were solved by locating spacers of thickness equal to the protruding bender length between platens and specimen. The testing system included a TTi TG1010 function generator and a Tektronix TDS220 oscilloscope to record input and output. Input excitation was a sine pulse of $20 \mathrm{kHz}$.

\section{RESULTS}

\section{Cross-check of dynamic moduli}

Table 2 presents the compression and longitudinal wave velocity measurements made on specimens 1 to 4 and the elastic moduli and Poisson's ratios computed from the measured velocities. Note that, in agreement with previous findings by Consoli et al. (2009) and Rios Silva et al. (2009), the ordering of the stiffness values is generally well predicted by the material index $\eta / C_{\mathrm{IV}}{ }^{0 \cdot 21}$.

Figure 5 shows the shear wave arrival time that would be expected from the previous measurements on top of the bender traces obtained with the Porto specimens. It seems that a conventional first-break arrival time selection would be very close to the expected shear wave arrival time. For other stiff materials, Arroyo et al. (2010) have shown similar results even with protruding transducers.

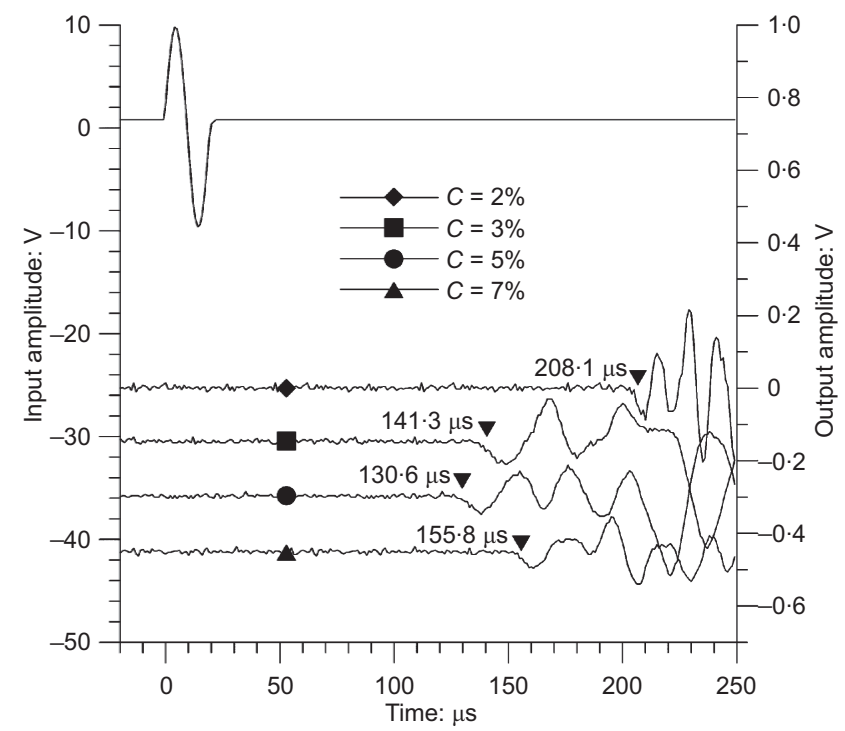

Fig. 5. Bender element traces with arrows indicating theoretical arrival time of the shear wave deduced from compression and longitudinal wave measurements

\section{Shear stiffness evolution}

Shear moduli obtained from all the bender elements tests are listed in Table 3. The results offer some insight into the curing influence on specimen shear stiffness. Despite the use of fast-set cement, it would seem that at least 3 weeks are necessary for shear stiffness to stabilise. Measurements taken while the specimen is curing (at 7 days) were intrinsically more variable. This may explain some of the stiffness variability noticed by Rios Silva et al. (2009).

\section{Longitudinal resonant frequencies}

The specimen FRFs obtained with the longitudinal wave measurements (see equation (6)) were further examined. Using the measured $V_{\mathrm{L}}$, resonant frequencies were computed using the appropriate relation for longitudinal resonance in a bar of length $L$

$$
f_{n}=\frac{n V_{\mathrm{L}}}{2 L}
$$

where $n$ is the resonant mode number.

Figure 6 shows the longitudinal resonant frequencies for specimen 3 computed from equation (8). It also identifies their peaks on the FRF of the specimen. All the modes but one can be clearly identified with longitudinal resonances.

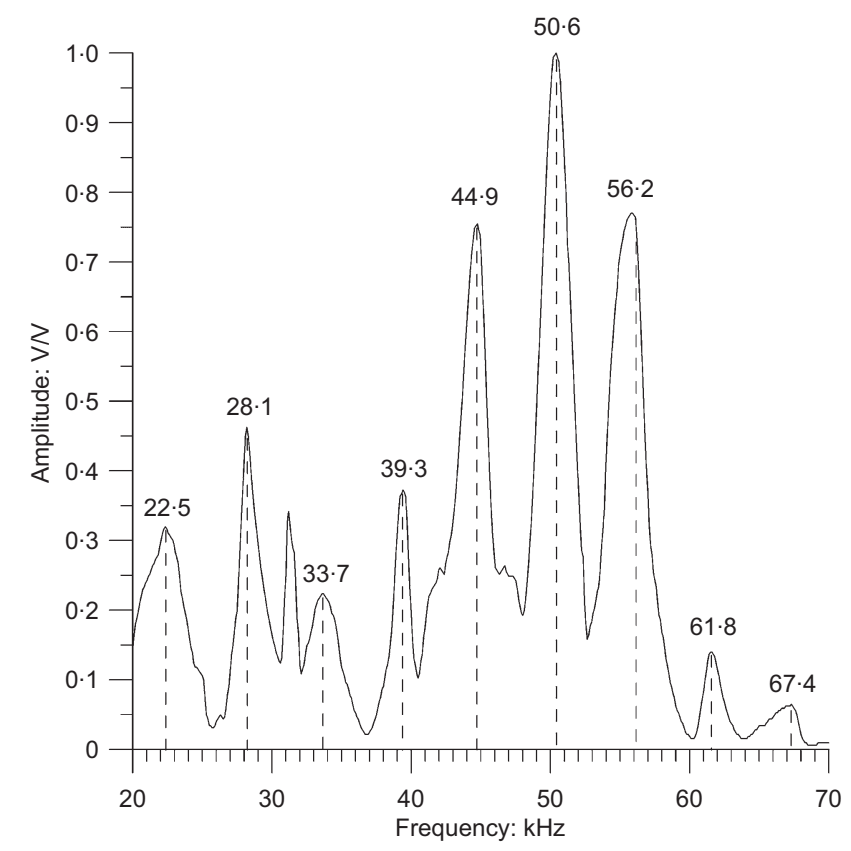

Fig. 6. FRF $F_{S}$ of specimen 3 and resonant modes 
Table 3. Shear modulus $G$ of specimens computed from the bender element tests

\begin{tabular}{|c|c|c|c|c|}
\hline \multirow{2}{*}{ Shear modulus $G$ : $\mathrm{MPa}$} & \multicolumn{4}{|c|}{ Specimen } \\
\hline & 5 & 6 & 7 & 8 \\
\hline $\begin{array}{l}7 \text { days } \\
14 \text { days } \\
21 \text { days } \\
28 \text { days }\end{array}$ & $\begin{array}{l}525 \\
704 \\
801 \\
803\end{array}$ & $\begin{array}{l}1437 \\
1785 \\
1950 \\
1985\end{array}$ & $\begin{array}{l}1555 \\
1895 \\
2114 \\
2196\end{array}$ & $\begin{array}{l}1085 \\
1310 \\
1413 \\
1429\end{array}$ \\
\hline
\end{tabular}

Table 4. Damping ratio and highest FRF peak's corresponding frequency and amplitude for each specimen

\begin{tabular}{|c|c|c|c|c|}
\hline & \multicolumn{4}{|c|}{ Specimen } \\
\hline & 1 & 2 & 3 & 4 \\
\hline $\begin{array}{l}\text { Density: } \mathrm{kg} / \mathrm{m}^{3} \\
\text { Peak amplitude: } \mathrm{V} \\
\text { Frequency: } \mathrm{kHz} \\
f_{1}: \mathrm{kHz} \\
f_{2}: \mathrm{kHz} \\
\text { Damping ratio: } \%\end{array}$ & $\begin{array}{c}1857 \\
1 \cdot 023 \\
49 \cdot 6 \\
48 \cdot 6 \\
52 \cdot 1 \\
3 \cdot 5\end{array}$ & $\begin{array}{c}2046 \\
1 \cdot 189 \\
50 \cdot 6 \\
49 \cdot 5 \\
51 \cdot 5 \\
2 \cdot 0\end{array}$ & $\begin{array}{c}1973 \\
0 \cdot 950 \\
48 \cdot 8 \\
48 \cdot 7 \\
49 \cdot 8 \\
1 \cdot 1\end{array}$ & $\begin{array}{c}1878 \\
1 \cdot 102 \\
51 \cdot 5 \\
50 \cdot 3 \\
52 \cdot 8 \\
2 \cdot 4\end{array}$ \\
\hline
\end{tabular}

\section{Damping ratios of longitudinal resonant modes}

Using the half-power bandwidth method, the damping ratio was estimated for all the longitudinal resonant modes in all specimens. Table 4 lists the amplitudes, peak and half-power frequencies and damping ratios $\left(\xi_{\mathrm{k}}\right)$ for the highest peak of specimens $1-4$. The results show that $\xi_{\mathrm{k}}$ has an inverse relation with Young's modulus, but the damping values are high if compared with longitudinal damping values for cemented and uncemented sands (Saxena \& Reddy, 1989; Khan et al., 2011).

Joint consideration of the damping ratios computed from the resonant frequencies in the frequency bandwidth $20-70 \mathrm{kHz}$ does not show a clear trend. More powerful inversion procedures, such as the complex exponential method illustrated by Tallavó et al. (2011), may offer better results.

\section{CONCLUSIONS}

The inclusion of a same-material disc ensured good coupling between the transducers and the specimen for the generation of longitudinal waves. Full dynamic characterisation of the specimen using the transfer function and the impulse response functions (FRF, IRF) was possible by the deconvolution of the effect of the transducers. The longitudinal wave velocity computed from the IRFs was complemented with the high-frequency compression wave measurements using ultrasonic transducers. These measurements provide two independent moduli of an isotropic elastic material (and therefore allow the evaluation of Young's modulus, shear modulus and Poisson's ratio). However, the evaluation of damping ratio using the half-bandwidth method requires further investigation.

In the testing configuration employed there was very little difference between a conventional first-break approach to identify shear wave arrival time in bender traces. This might be attributed to side reflection noise minimisation due to the non-protruding transducer installation.

Despite using high initial strength cement, shear stiffness was still improving noticeably in 21-day-old soil-cement specimens.

\section{ACKNOWLEDGEMENTS}

The authors thank Fernado Tallavó PhD, University of Waterloo, for sharing the software that allowed automatic evaluation of the inverse process. This research was developed under the activities of FCT (Portuguese Foundation for Science and Technology) research unit CEC, in FEUP, namely PTDC/ECM 099475/2008 project, financed by European Community (QREN/UE/FEDER) on the Operational Program for Competitive Factors 'COMPETE'.

\section{REFERENCES}

Amaral, M. F. (2009). Dynamic shear modulus evaluation in soilcement mixtures using time domain ultrasonic impulses and recording the resonant frequencies with Fourier spectral analysis. MEng thesis. University of Porto, Portugal (in Portuguese).

Arroyo, M., Pineda, J. A. \& Romero, E. (2010) Shear wave measurements using bender elements in argillaceous rocks. Geotech. Test. J. 33, No. 6, 488-498.

Consoli, N. C., Viana da Fonseca, A., Caberlon Cruz, R \& Heineck, K. S (2009). Fundamental parameters for the stiffness and strength control of artificially cemented sands. J. Geotech. Geoenviron. Engng ASCE 135, No. 9, 1347-1353.

Ewins, D. J. (1991). Modal testing: theory and practice. New York, NY, USA: Wiley.

Graff, K. F. (1991). Wave motion in elastic solids. Oxford, UK: Dover.

Khan, Z., Majid, A., Cascante, G., Hutchinson, D. J. \& Pezeshkpour, P. (2006). Characterization of a cemented sand with the pulse-velocity method. Can. Geotech. J. 43, No. 3, 294-309.

Khan, Z., Cascante, G., \& El-Naggar, H. (2011). Dynamic properties of cemented sands using ultrasonic waves. Can. Geotech. J. 48, No. 1, 1-15.

Kolsky, H. (1953). Stress waves in solids. Oxford, UK: Oxford University Press.

Kramer, S. L. (1996). Geotechnical earthquake engineering. Upper Saddle River, NJ, USA: Prentice Hall.

Lings, M. L. \& Greening, P. D. (2001). A novel bender/extender element for soil testing. Géotechnique 51, No. 8, 713-717.

Rios Silva, S., Viana da Fonseca, A \& Consoli, N. C. (2009). Strength and stiffness properties of mixtures of granitic soilcement. Proc. 17th Int. Conf. Soil Mech. Found. Engng, Alexandria, 1, 312-315.

Santamarina, J. C. \& Fratta, D. (2005). Discrete signals and 
inverse problems: an introduction for engineers and scientists. New York, NY, USA: Wiley.

Saxena, S. K. \& Reddy, K. R. (1989). Dynamic moduli and damping ratios for Monterey No. 0 sand by resonant column tests. Soils and Found. 29, No. 2, 37-51.

Tallavó, F., Cascante, G. \& Pandey, M. D. (2011). Ultrasonic transducers characterisation for evaluation of stiff geomaterials. Géotechnique 61, No. 6, 501-510.

Thurston, R. N. (1992). Elastic waves in rods and optical fibers. $J$. Sound Vib. 159, No. 3, 441-467.
Viana da Fonseca, A., Carvalho, J., Ferreira, C., Santos, J. A, Almeida, F., Pereira, E., Feliciano, J., Grade, J. \& Oliveira, A. (2006). Characterization of a profile of residual soil from granite combining geological, geophysical, and mechanical testing techniques. Geotech. Geol. Engng 14, No. 5, 13071348.

Viana da Fonseca, A., Ferreira, C \& Fahey, M. (2009). A framework interpreting bender element testing. Combining time-domain and frequency domain methods. Geotech. Testing J. 32, No. 2, 91-107.

\section{WHAT DO YOU THINK?}

To discuss this paper, please email up to 500 words to the editor at journals@ice.org.uk. Your contribution will be forwarded to the author(s) for a reply and, if considered appropriate by the editorial panel, will be published as a discussion. 